\title{
Double Reduplications in Parallel ${ }^{1}$
}

\author{
Suzanne Urbanczyk \\ University of Massachusetts/University of British Columbia
}

A leading idea in Optimality Theory is parallelism of constraint satisfaction (Prince and Smolensky 1993: §2). In parallelist Optimality Theory (henceforth OT) only fully-formed candidates are generated and evaluated for goodness against the entire constraint hierarchy. There are no intermediate stages. This paper examines a number of issues that parallelism raises in deriving doubly reduplicated words.

Northern Lushootseed (Puget Salish) exhibits a pattern of reduplication which appears to require an intermediate stage.

(1) Lushootseed Reduplication (Hess and Hilbert 1976, 2: 165)

$\begin{array}{lllr}\text { a } & \text { bədá? } & \text { child, offspring } & \\ \text { b } & \text { bí-bəda? } & \text { small child } & \text { DIMINUTIVE } \\ \text { c } & \text { bəd-bədá? } & \text { children } & \text { DISTRIBUTIVE } \\ \text { d } & \text { bí-bəd-bəda? } & \text { dolls; litter [of animals] } & \text { DIM-DIST } \\ \text { e } & \text { bí-bi-bəda? } & \text { young children } & \text { DIST-DIM }\end{array}$

The root is shown in (1a). In (1b) the diminutive is $\mathrm{C}_{1} \mathbf{1}^{-}$with a fixed segment in its nucleus. In (1c) the distributive is a $\mathrm{C}_{1} \mathrm{~V}_{1} \mathrm{C}_{2^{-}}$prefix with the base vowel in its nucleus. The diminutive and distributive reduplicative morphemes can co-occur on a number of stems (Hess 1967; Broselow 1983). When the diminutive precedes the distributive, as in (1d), the reduplicative affixes are the same as in the single reduplications: $\mathrm{C}_{1} 1-\mathrm{C}_{1} \mathrm{~V}_{1} \mathrm{C}_{2}-$. However, when the distributive precedes the diminutive, as in (1e), the pattern is: $\mathrm{C}_{1} \mathrm{i}^{-} \mathrm{C}_{1} \mathrm{i}-$. The distributive affix is not its usual $\mathrm{C}_{1} \mathrm{~V}_{1} \mathrm{C}_{2}$ - shape. In fact, it is identical to the diminutive reduplicant, suggesting that the stem in (1e) is derived from the stem in (1b).

\footnotetext{
${ }^{1}$ For comments on an earlier draft of this paper, I would like to thank John Alderete, Jill Beckman, Mike Dickey, Joe Pater, Sharon Peperkamp, Sharon Rose, Lisa Selkirk, Laura Walsh, participants of the Correspondence Theory Seminar at UMass (Spring 1995), and an anonymous reviewer. I am grateful to John McCarthy for insightful comments and guidance during each stage of research. Special thanks to Laura Benua for many inspiring discussions. All errors are my own. This work was supported in part by SSHRCC Doctoral Fellowship \#752-92-0691.
} 
The bi-bi-badà? pattern of double reduplication presents an interesting challenge to parallelist OT because it has provided evidence for morphological subjacency and cyclicity in double reduplications (Broselow 1983). Every theory of reduplication which has a copying procedure, must invoke the cycle to get the correct shape and fixed segmentism in Lushootseed. The use of the cycle differs quite radically from the analysis developed in this paper, where there are no intermediate stages. The identity between the distributive and diminutive morphemes in bi-bi-badà? will be shown to be an instance of overapplication of fixed segmentism in reduplication, similar to the reduplicative identity effects analyzed by McCarthy and Prince (1995). By showing that parallelism may be maintained in the face of a process of word-formation which was necessarily cyclic, this study provides further support for the non-derivational nature of OT.

In section 1 I present the analysis developed in Broselow (1983), discussing why the cycle is necessary in double reduplications. In the remainder of the paper I will show that in OT no intermediate stage is required. Parallelism of constraint evaluation results in the correct size and fixed segmentism of all reduplicative affixes, regardless of the morphological composition of the word. Section 2 presents a discussion of parallelism in OT and lays out the basic framework for reduplication. In section 3 a comprehensive analysis of the diminutive and distributive patterns of reduplications is presented. Finally, section 4 shows that the constraint rankings obtained for the single reduplications also account for the double reduplications: nothing special need be said of the doubly reduplicated stems. I will also discuss what would be required of a serial analysis, arguing that the parallel approach is formally more simple than one involving intermediate stages.

\section{Cyclicity and double reduplications}

Broselow (1983) presents the only previous account of Lushootseed double reduplications. She crucially requires intermediate stages and assumes two principles for the formation of double reduplications: cyclicity and subjacency. Cyclicity, a standard assumption of Lexical Phonology (Kiparsky 1982; Mohanan 1986), states that 'each reduplication affix involves a new cycle in the lexicon' (Broselow 1983: 327). It rules out forms like (2a), in which the distributive morpheme incorrectly copies the segmental material of the root. Subjacency 'prevents the copying of phonemic material across two or more bounding nodes, where "stem" is a bounding node for word-level rules' (Broselow 1983: 342). It rules out forms like (2b), in which the distributive copies segmental material which extends past the diminutive. For perspicuity I have underlined the portion of the word which supplies the segmental content of the distributive. 
(2) Distributive-Diminutive

$\begin{array}{ll}\text { dist. } & \text { dim } \\ \text { CVC } & \text { Ci } \\ \text { bəd } & \text { bi } \\ \text { bib } & \text { bi } \\ \text { bi } & \underline{\text { bi }}\end{array}$

(modified from Broselow 1983: 325)

stem

CVCVCVC

bəda?

bəda?

bəda? small children

The attested form is (2c), obeying cyclicity and subjacency.

Cyclicity and subjacency are both required to explain why the distributive is Cí in DIST-DIM stems. Given the structure of bíbibadà? in (3), the derivation proceeds as in (4) and (5).

$$
\left[_{\text {word }}\left[{ }_{\text {stem }} \operatorname{DIST}\left[_{\text {stem }} \mathrm{DIM}\left[_{\text {stem }} \text { bədá? }\right]\right]\right]\right]
$$

The first cycle produces $\left[_{\text {stem }} b\right.$ adá $]$.

On the second cycle the diminutive $\mathrm{Ci}$ skeleton is prefixed. The quality of the diminutive vowel is represented as a prespecified melody in the lexicon (see Marantz 1982). The melody contained in the subjacent stem (bəda ) is copied and associated from left to right. Finally, unassociated melodemes are erased.

$$
\begin{array}{lll}
\begin{array}{ll}
\text { dim. } \\
\text { i }
\end{array} & \text { stem } \\
\text { C V } & \text { C V C V C } & \\
\text { b } & \text { əda? } & \text { b ə d a ? }
\end{array}
$$

On the next cycle, the distributive CVC skeleton is prefixed. Subjacency ensures that only melodemes contained in the subjacent cycle (diminutive reduplication) are available for copy.

$$
\begin{array}{llll}
\text { dist. } & \text { dim. } & \text { stem } \\
\text { C V C } & \text { C V } & \text { C V C V C } & \\
\text { b i } & \text { b } & \text { b ə d a ? } \rightarrow \text { bibibəda? }
\end{array}
$$

The melody $b i$ is copied and associated. Because there are fewer melodemes than skeletal positions, a lone $\mathrm{C}$ slot remains unassociated and is erased at the end of the cycle.

Subjacency provides a principled explanation for the size alternation of the distributive affix. In DIM-DIST stems, the entire root is available for copy and the distributive is CVC. In DIST-DIM stems, only diminutive material is available for copy, hence the distributive is only bisegmental CV. While Broselow claims that Subjacency is a general property of reduplication theory, in section 3 I will present evidence against subjacency as an account of the size alternation. Rather than 
providing a morphological analysis, I will present evidence that a general process of anti-gemination in Lushootseed is active in restricting the size of the distributive reduplicant.

In the copy and associate model that Broselow adopts, cyclicity is required in double reduplications because the reduplicant (the phonological exponence of a reduplicative affix, a term coined by Cari Spring) and the base (the string supplying the phonological content) must be adjacent. The following forms show that the distributive reduplicant must copy adjacent material. The adjacency requirement is particularly observable in stems which have $\mathrm{a}_{1}$ í- diminutive reduplicant.

(6) Double Reduplications

a DIM-DIST: bí-bəd-bəda? dolls; litter [of animals]

b DIST-DIM: bí-bi-bəda? young children

In (a) the distributive is composed of the three segments to its immediate right. In (b) it is composed of the two segments (one of which is a fixed segment) to its immediate right. In this model of reduplication, the only way to achieve adjacency between reduplicant and base is to have cyclic application of segmental copying.

In fact, cyclicity is required to derive Lushootseed double reduplications in every theory of reduplication which has a process of copying: copy and associate (Marantz 1982), parafixation (Clements 1985; Mester 1986), and copy and trim (Steriade 1988). The following derivation, in which the stem $b$ ada? is copied twice, shows that parallel affixation results in non-adjacency of the outermost reduplicant and its base.
Parallel affixation
dist.
$\operatorname{dim}$.
stem
C V C
C V
C V C V C
b ə d a ?
b $ə d a ?$
b əd a $? \rightarrow$ *bəd-bi-bəda?

Nothing about copying theories of reduplication explains why parallel affixation cannot occur in Lushootseed. Thus each theory must invoke the cycle.

While in previous models, double reduplications must be formed cyclically, in OT they need not be. In OT, parallel affixation of both reduplicative morphemes can occur because reduplicant and base are adjacent in the output, and constraints evaluate outputs. In the next section I present an outline of the formal mechanism for reduplication in OT. In following sections I show that the shape and segmental content of both distributive alternants (CVC- and Cí-) result from general phonotactic constraints interacting with reduplicative constraints. 


\section{Parallelism in Optimality Theory}

In OT, parallelism refers to a property of Gen(erator). Only fully-formed candidates are emitted (see Prince and Smolensky 1993: $§ 2$ for details). These fullyformed candidates are evaluated for well-formedness against the entire constraint hierarchy. Because the pairing of input and output involves no intermediate stages, this necessarily entails that there is no cycle in strict parallelist OT. To have a cycle would require an intermediate stage.

Two studies which provide evidence for separate levels/strata in OT are McCarthy and Prince (1993: Appendix) and Kenstowicz (1994a). The motivation for distinct levels comes from constraint re-ranking. Note however, that Gen still emits fully-formed candidates at various stages. The different constraint rankings associated with separate strata is the hall-mark of a serial derivation in OT. (A restricted form of serialism, without constraint re-ranking, is proposed in Benua (1995) to account for identity effects in truncated words.)

The prediction that parallelism makes for doubly reduplicated stems is clear. If one constraint hierarchy can derive single and double reduplications, then both are formed in parallel. If a separate constraint ranking is required for double reduplications, then there must be an intermediate stage.

The unique feature of reduplicative morphemes is that phonological invariance is defined by overall shape rather than segmental content, the segmental content being supplied by a base. McCarthy and Prince (1994a), in their Utrecht talks, outline two general mechanisms for deriving invariant shape and segmental dependency: Generalized Template Specification and Generalized Template Satisfaction. The need to generalize comes from the goal to eliminate as many reduplication specific conditions from the grammar as possible. I outline first how reduplicative morphemes get variable segmentism, and then how shape invariance is achieved. The following echoes a more detailed discussion in McCarthy and Prince (1995).

Reduplicative morphemes are represented in the input as abstract, phonologically empty $\mathrm{RED}_{\mathrm{i}}, \mathrm{RED}_{\mathrm{j}}, \ldots$, where $\mathrm{RED}_{\mathrm{i}}$ is specified only for morphological classification. The input is necessarily empty because the exact segmental content can only be determined by the base to which it is attached. The phonological exponence of $\mathrm{RED}_{\mathrm{i}}$ is the output reduplicant string.

The segmental content of a reduplicant is achieved via a correspondence relation with a base, where base is defined as an adjacent string in the output (McCarthy and Prince 1993). For prefixing reduplication, the base is the string immediately to the right; for suffixing, it is to the left of the reduplicant. 
Correspondence is a relation pairing up strings of various types and is defined as follows. $^{2}$

Correspondence (McCarthy and Prince 1995)

Given two strings $S_{1}$ and $S$, related to one another by some linguistic process, correspondence is a function $f$ from any subset of elements of $S_{1}$ to $S_{2}$. Any element $\alpha$ of $S_{1}$ and any element $\beta$ of $S_{2}$ are correspondents of one another if $\alpha$ is the image of $\beta$ under correspondence; that is, $\alpha=f(\beta)$.

Correspondence between base and reduplicant holds between output strings. It replaces the inherently procedural operations of copying and association in obtaining segmental identity between base and reduplicant. Adjacency between base and reduplicant is obtained via the definition of base.

Gen is free to supply any string as the reduplicant, and identity between base and reduplicant is evaluated by a number of constraints which ensure goodness of correspondence. Faithfulness of reduplicant to base include such properties as: whether the reduplicant begins or ends like its base, whether it reflects the same linear order as the base, whether it contains material not in the base, and whether it includes everything in the base. Two key faithfulness constraints are MAX and DEP: MAX ensures total copy and DEP bars all non-base material. The definitions are provided below, where Domain refers to the set of correspondents in $S_{1}$ and Range refers to the set of correspondents in $S_{2}$; for reduplication $S$ is the base and $S$ is the reduplicant.

$$
\begin{aligned}
& \text { MAX } \\
& \text { Every element in } S_{1} \text { has a correspondent in } S_{2} \text {. That is Domain }(f)=S_{1} \\
& \text { DEP } \\
& \text { Every element in } S_{2} \text { has a correspondent in } S_{1} \text {. That is Range(f) }=S_{2}
\end{aligned}
$$

When MAX and DEP are obeyed, reduplication is total. Partial reduplication results when MAX is violated under compulsion of some higher ranked constraint(s).

The invariance associated with reduplicative morphemes has typically been associated with a template of some form (Marantz 1982; McCarthy and Prince 1986, 1990). However, McCarthy and Prince (1994a; Pt 1) propose that the invariance need not be defined templatically. ${ }^{3}$ Rather, it can be determined by the interaction of faithfulness constraints with general phono-constraints.

\footnotetext{
${ }^{2}$ Initially, correspondence related only reduplicant and base, however, recently its been extended to input-output strings (McCarthy and Prince 1995) and truncated-base words (Benua 1995).

${ }^{3}$ A similar idea has been proposed by Steriade (1988), who shows that templates can be composed of two conditions: one on phonological markedness and another on weight.
} 
(10) Generalized Template (MP 1994a: Pt. 1)

Templatic targets are determined by structural conditions, which, interacting through constraint ranking, properly characterize the desired invariance structure.

A central idea to Generalized Templates is that reduplicative morphemes need only be specified for morphological category, where MCat can be Root, Afx, or Stem (McCarthy and Prince 1994a: Pt. 1). The shape invariance results from canonical morpheme shape emerging in reduplication, where the shape of reduplicants parallels the shape of morphemes in a language.

In addition to phono-constraints, Generalized Template theory crucially requires constraints which refer to morphological and prosodic categories. These MCat/PCat constraints also serve to restrict the size of reduplicants. One such constraint proposed by McCarthy and Prince is Afx $\leq \sigma$.

(11) Afx $\leq \sigma$ (McCarthy and Prince 1994b; Pt1)

The phonological exponent of an affix is no larger than a syllable.

Partial reduplication results because $\mathrm{Af} x \leq \sigma$ dominates MAX.

The basic features of reduplication are summarized as RED being a phonologically empty morpheme, achieving its segmental content via correspondence with a base. Size restrictors and phono-constraints interact with MAX to achieve the invariant shape. Finally, something must be said about languages with multiple reduplicative morphemes.

Each reduplicative morpheme has its own correspondence relation. Because each reduplicative morpheme necessarily has a different shape, different conditions must figure into determining its invariance. As a consequence, each abstract $R_{E D}$ comes with an attendant set of faithfulness constraints. So, in doubly reduplicated words, the output will contain two reduplicants and two bases, evaluated by two RED $_{\mathrm{i}}$-specific sets of faithfulness constraints. It is important to note that the ranking of the faithfulness constraints for distinct reduplicative morphemes is expected to differ.

Having introduced the basic assumptions and theoretical framework, I now turn to the analysis. First I present the single reduplications. Then I show that the rankings obtained for words with only one reduplicative morpheme also account for words with double reduplications. This result is expected under the strictest view of parallelism in OT. 


\section{Single reduplications}

The complex and varied patterns of reduplication exhibited in Northern Lushootseed (a dialect group of Puget Salish) have been a topic of several studies (Haeberlin 1918; Hess 1966; Hess and Hilbert 1976; Broselow 1983; Broselow and McCarthy 1984; Davis 1985; Bates 1986; Kirkham 1992). The most recent reference on Lushootseed notes six distinct categories of reduplicative affix (Bates, Hess and Hilbert 1994). Of these, diminutive and distributive are the most common and are the basis of this study.

\subsection{Diminutive}

Diminutive reduplication indicates smallness, diminished action and endearment (Bates, Hess and Hilbert 1994). It is characterized by the following patterns.

$$
\text { Lushootseed Diminutive (BHH 94) }{ }^{4}
$$

$\begin{array}{lll}\text { a } & \text { čáləs } & \text { hand } \\ & \text { hiw-il } & \text { go ahead } \\ \text { b } & \check{c ́}^{\prime} \lambda \text { 'á? } & \text { rock } \\ & \text { təláw-il } & \text { run } \\ & \text { s-duuk }^{\mathrm{w}} & \text { knife } \\ \text { c } & \text { s-duk }^{\mathrm{w}} & \text { bad } \\ & \text { súq }^{\mathrm{w}} \mathrm{a} \text { ? } & \text { younger sibling } \\ \text { d } & \text { buus } & \text { four } \\ & \text { Xəc-bid } & \text { afraid }\end{array}$

\begin{tabular}{|c|c|}
\hline čá+čaləs & little hand \\
\hline hi+hiwil & go ahead a bit \\
\hline $1+\check{c}^{\prime} \lambda \lambda^{\prime} \mathrm{a}$ & little rock \\
\hline +tolaw'-il & jog \\
\hline dít+duuk ${ }^{\mathrm{w}}$ & small knife \\
\hline dú? $+\mathrm{duk}^{\mathrm{w}}$ & riff-raff \\
\hline$?+$ suq $^{\text {w'a? }}$ & little younger sibling \\
\hline & four little items \\
\hline Xәc-bic & a little afraid of it \\
\hline
\end{tabular}

Stress always falls on the reduplicant (which is underlined). While there are four alternants, $\mathrm{C}_{1} \mathrm{~V}_{1^{-}}, \mathrm{C}_{1} 1^{-}, \mathrm{C}_{1} \mathrm{~V}_{1}$ ?-, and $\mathrm{C}_{1} \mathrm{R}^{\mathrm{P}}$-, Bates (1986) provides evidence that the basic alternant is $\mathrm{C}_{1} \mathrm{~V}_{1}{ }^{-}$. First, Bates argues that the glottal stop in (12c) and (12d) is not a part of the reduplicative affix. ${ }^{5}$ Thus we are left with $C_{1} V_{1}$-and $C_{1} 1-$. Bates also observes that the choice between $\mathrm{C}_{1} \mathrm{~V}-(12 \mathrm{a} / 12 \mathrm{c})$ and $\mathrm{C}_{1} \mathrm{1}^{-}(12 \mathrm{~b} / 12 \mathrm{~d})$ is entirely predictable: $\mathrm{C}_{1} \hat{1}^{-}$when the stem contains schwa, a long vowel or begins with a consonant cluster, and $\mathrm{C}_{1} \mathrm{~V}$ - elsewhere.

The analysis requires two parts: first, specifying the morphological category of the diminutive, then determining the constraint interaction to derive the two

\footnotetext{
${ }^{4}$ All data are taken from Bates, Hess, and Hilbert (1994) Lushootseed Dictionary (henceforth BHH 94). Unless noted, all observations are of the Northern dialect group. The phoneme inventory of

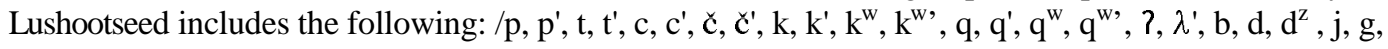
$\mathrm{g}^{\mathrm{w}}, \mathrm{s}, 4, \breve{s}, \mathrm{x}^{\mathrm{w}}, \mathrm{X}, \mathrm{X}^{\mathrm{w}}, \mathrm{h}, \mathrm{l}, \mathrm{l}^{\prime}, \mathrm{y}, \mathrm{y}^{\prime}, \mathrm{w}, \mathrm{w}^{\prime} \mathrm{i}, \mathrm{ii}, \mathrm{u}, \mathrm{uu}, \mathrm{a}, \mathrm{aa}$, ə/. Following Salish convention, = indicates a lexical suffix, - indicates a fixed segmental affix, and + indicates a reduplicative affix.

${ }^{5}$ Bates (1986) analyzes the glottal stop as occuring post-lexically, on open stressed syllables.
} 
predictable alternants. The diminutive is analyzed as an affix: RED-DIM=Afx. ${ }^{6}$ The two alternants, $\mathrm{C}_{1} \mathrm{~V}_{1^{-}}$and $\mathrm{C}_{1} 1^{-}$, have the same shape, but differ in the presence of a fixed segment. The basic shape is analyzed first, then the fixed segmentism. The fixed segmentism is only found with marked bases, and is analyzed as an instance of unmarked structure emerging in reduplication (McCarthy and Prince 1994b).

The CV- shape results because NoCoda (a constraint barring coda consonants: Prince and Smolensky 1993) dominates MAX-DIM. The size restrictor Af $\leq \sigma$ keeps the reduplicant monosyllabic.

\section{(13) Afx $\leq \sigma>>$ NoCoda $\gg>$ MAX-DIM}

\begin{tabular}{|cc||c|c|c|}
\hline s-DIM-čaləs & Afx $\leq \sigma$ & NoCoda & MAX-DIM \\
\hline \hline a $\quad$ a čá-čaləš & & $*$ & $* *$ \\
\hline b $\quad$ čál-čaləs & & $* * !$ & $*$ \\
\hline c $\quad$ ćálə-čaləs & $* !$ & $*$ & $* * *$ \\
\hline
\end{tabular}

Candidate a, the optimal form, obeys $\mathrm{Afx} \leq \boldsymbol{\sigma}$ and NoCoda but fares the worst on MAX-DIM. Candidate $b$ violates NoCoda twice, which proves fatal. Candidate $\mathrm{c}$ is suboptimal because it is bisyllabic. The correct shape is obtained because the correspondence constraint MAX-DIM is subordinate to the size restrictor Afx $\leq \sigma$ and the syllable-markedness constraint NoCoda.

The analysis of the Cí- alternant draws on the descriptive insights of Bates (1986: 11): '[f]orms take Ci- if CV- prefixation is prevented by independent principles'. Essentially, when the base cannot provide an optimal nucleus for the reduplicant, $i$ epenthesis results. The diminutive is Cí under the following conditions: with cluster-initial roots, with roots which contain long vowels, and with roots whose initial vowel is schwa.

The fixed segmentism of the diminutive is not represented as a prespecified melody in the lexicon (McCarthy and Prince 1986 et seq.). Because the fixed segment is 'epenthetic' (in the sense that it is not present in the base), all $\mathrm{C}_{1}{ }^{1}$ - alternants violate DEP-DIM, which bars non-base material from the reduplicant.

DEP: Every element of $\mathrm{S}_{2}$ has a correspondent in $\mathrm{S}_{1}$. That is Range $(\mathrm{f})=\mathrm{S}_{2}$.

\footnotetext{
${ }^{6}$ I will indicate the diminutive and distributive reduplicative constraints by suffixing the labels DIM and DIST respectively.
} 
Non-correspondence is compelled by a number of constraints, the general pattern falling under the ranking schema of the Emergence of the Unmarked (McCarthy and Prince 1994b; 1995).

(15) Emergence of the Unmarked (MP 1995)

$$
\text { Faithfulness }_{/ / \mathrm{O}} \text { > Phono-Constraint }>\text { Faithfulness }{ }_{\mathrm{B} / \mathrm{R}}
$$

Unmarked structure emerges in reduplication because a phono-constraint intervenes between input/output and base/reduplicant faithfulness. The cost of maintaining faithfulness of the input/output domain is that the output is marked with respect to the phono-constraint. The cost of obeying the phono-constraint in the reduplicant is less than perfect identity. Space limitations preclude a full analysis of the diminutive, so only the aspects relevant to base/reduplicant faithfulness will be presented in the following discussion. For further details see Urbanczyk (in prep).

In cluster-initial roots, the reduplicant has only a simplex onset, while the base has a complex onset. The relevant phono-constraint is *Complex.

*Complex (Prince and Smolensky 1993: 87)

No more than one $\mathrm{C}$ or $\mathrm{V}$ may associate to any syllable position node.

*Complex ensures that the reduplicant has a simplex onset, but a further constraint is need to rule out $\mathrm{C}_{1} \mathrm{~V}_{1}$, in which the second consonant is skipped over to copy the base vowel. This segment skipping pattern is attested in the Sanskrit perfective pattern: pa-prath 'spread' (Shaw 1995; Steriade 1988; Whitney 1889: §590; McCarthy and Prince 1986). Lushootseed differs minimally from Sanskrit, because Sanskrit tolerates skipping while Lushootseed does not. The relevant faithfulness constraint is the No-Skipping portion of Contiguity.

(17) Contiguity (No-Skipping in B) (MP 1995)

The portion of $S_{1}$ standing in correspondence forms a contiguous string, as does the correspondent portion of $\mathrm{S}_{2}$. That is, Domain(f) is a single contiguous string.

The $\mathrm{C}_{1}$ i- pattern emerges because ${ }^{*}$ Complex and No-Skipping are obeyed at the expense of $\mathrm{DEP}_{\mathrm{DIM}}$ as the following tableau shows. 
(18) *Complex, No-Skipping >> Dependence DIM

\begin{tabular}{|c|c|c|c|c|}
\hline \multicolumn{2}{|c|}{ DIM-č $\lambda$ 'a? } & *Complex & No-Skipping & Dep $_{\text {DIM }}$ \\
\hline $\mathrm{a}$ & 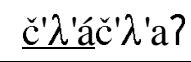 & $* *$ ! & & \\
\hline b & 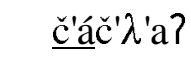 & $*$ & $* !$ & \\
\hline $\mathrm{c}$ & 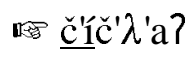 & $*$ & & $*$ \\
\hline
\end{tabular}

The preceding ranking derives the Lushootseed pattern, while the reverse ranking (Dependence dominating No-Skipping) derives the Sanskrit pattern.

The cluster-initial roots show that the fixed segment does not have a correspondent in the base. If the fixed segment stood in correspondence with the base vowel, the reduplicant would violate No-Skipping. I now turn to the question of the quality of the fixed segment.

The fixed segment is $i$ because it is the least marked nucleus under stress. The unmarkedness of $i$ follows from two assumptions. $i$ is specified with the feature [coronal] (Clements 1991), and because * $\mathrm{Pl} /$ Cor is universally low ranked, inserting [coronal] is more harmonic than inserting other place features. The 'under stress' condition is important because, while schwa is the regular epenthetic vowel (Hess and Hilbert 1976; Broselow 1983; Bates 1986), it is marked when stressed. Recall that the diminutive is always assigned primary stress. The only time that schwa is stressed in Northern Lushootseed is when there are no full vowels in a word. Hess (1977) describes the stress system as follows: stress falls on the first full vowel, or if the stem contains only schwas, then stress falls on the first schwa. ${ }^{7}$ The Cí- reduplicant avoids stressing schwa because the unmarked vowel $i$ can be made available in reduplication.

This brief explanation of the quality of the fixed segment also provides the key to the analysis of a second set of roots. Recall that the fixed segment occurs with roots containing schwa. The analysis relates vowel quality with stress. Schwa is stressed only under duress, so with diminutive reduplication, stressed $i$ is prefered over stressed $\partial$.

Support for relating stress and vowel quality comes from the following cluster-initial and schwa vowelled roots which would otherwise be exceptional.

(19) Diminutives with Non-Initial Stress

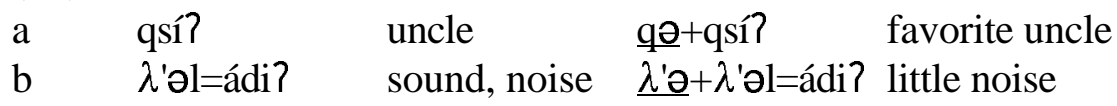

\footnotetext{
${ }^{7}$ This predictable stress can be overridden by some inherently stressed suffixes. Prefixes are never stressed, providing evidence that the prosodic word coincides with the left edge of the root.
} 
Here the fixed segment is schwa rather than $i$, but this is expected because stress does not fall on the diminutive. Presumably, these are cases of inherent stress over-riding the regular pattern of initial stress. The analysis of the schwa-vowelled roots requires a brief excursus on the assignment of stress and the proposed phono-constraint *Stressed-schwa.

The unstressability of schwa is common cross-linguistically. In addition to Northern Lushootseed, there are Dutch (Kager 1991), English, Eastern Cheremis (Hayes 1980), French (Selkirk 1977), Indonesian (Cohn 1989), and several languages discussed in Kenstowicz (1994b: Aljutor, Chukchee, Mari and Mordwin). ${ }^{8}$

Compared to other Salish languages, Northern Lushootseed has a fairly predictable stress pattern. The following ranking presents the basic interactions, ensuring that stress falls on the first full vowel, otherwise, stress falls on the first schwa. The prevalence of initial stress shows that feet are trochaic in Lushootseed. As their names imply, *Unstressed-V bars non-stressed full vowels, and *Stressedschwa bars stressed schwa. The alignment constraint ensures that feet are initial, where foot form is trochaic.

*Unstressed-V >> Align-L(PrWd, Ft), *Stressed-schwa

No ranking can be determined between Align-L(PrWd, Ft) and *Stressed-schwa.

Diminutives of roots with schwa show that the preceding micro-hierarchy dominates Dep-DIM. The following tableau shows that this constraint ranking accounts for the fixed segment, initial stress, and secondary stress on a following full vowel.

\footnotetext{
8 There are several approaches to formalizing *Stressed-schwa. Language-internal evidence supports Kenstowicz's (1994b) sonority-based proposal, where prominence peaks are preferentially more sonorous vowels. Schwa is the least sonorous vowel, and makes the worst prominence peak. A second aspect of Kenstowicz's proposal is that sonorous vowels are marked when unstressed. In Lushootseed, /a/ is the only vowel that reduces to schwa when unstressed. Kenstowicz's proposal relates these two facts. Kager (1991) proposes that schwa is mora-less at early stages of syllabification (consistent with being mora-less in the input). Itô (personal communication) suggests that schwa cannot be stressed because the head of a stressed foot must be headed by a vowel feature. If schwa is placeless (and [place] is the head of a segment as Itô and Mester 1993 propose), then schwa cannot be stressed because a headless vowel cannot head a stressed foot.
} 
(21) *Unstress-V >> Align-L, *Stress-ə >> Dep-DIM

\begin{tabular}{|c|c|c|c|c|}
\hline DIM-bəda? & *Unstress-V & Align-L & *Stress-ə & Dep-DIM \\
\hline $\mathfrak{d}^{205}$ bíbədà? & & & & * \\
\hline b bə̧bədà? & & & $* !$ & \\
\hline c bə̧bədá? & & $* !$ & & \\
\hline d bəobəda? & $* !$ & & * & $*$ \\
\hline
\end{tabular}

The optimal candidate only violates Dep-DIM, while all the suboptimal candidates violate at least one of the higher ranked constraints. The preceding tableau shows that the initial stress on diminutives follows the regular pattern of the language. Because Dep-DIM is low-ranking, a fixed segment occurs in the nucleus of the reduplicant. Once again the pattern is consistent with the ranking of the emergence of the unmarked, where high-ranking Dependence $\mathrm{I}_{\mathrm{I} O}$ is not indicated, ${ }^{*}$ Stressed-schwa being the intervening phono-constraint (because schwa is stressed in non-reduplicated stems).

When the root contains a long vowel, the relevant phono-constraint which dominates Dep-DIM is No-Long-V.

$$
\begin{aligned}
& \text { No-Long-V (Prince and Smolensky 1993; Rosenthall 1994) } \\
& * \underset{\sigma}{\mu} \operatorname{\mu } \\
& \mathrm{V}
\end{aligned}
$$

While the base contains a long vowel, the reduplicant contains a fixed vowel, not a shortened version of the base vowel, so a further constraint is required to rule out a reduplicant with a short base vowel.

Following Bates (1986), I analyze the failure to copy a portion of the long vowel as a result of transfer. Clements (1985) introduced the term transfer to refer to cases of reduplication which carry over aspects of syllable structure, such as vowel length and glide-hood, from base to affix (see also Levin 1983; McCarthy and Prince 1988). Transfer is formalized as a constraint on correspondence below. ${ }^{10}$

${ }^{9}$ For a different conception of No-Long-V see Itô and Mester (1995).

${ }^{10}$ It is not clear whether Transfer should be generalized to include onset-hood and/or coda-hood. If so, the definition of Transfer can include onset-hood by including zero as a value for the variable. 
(23) Transfer $\left(\mathrm{S}_{1}, \mathrm{~S}_{2}\right)=(\mathrm{B}, \mathrm{R})$

If $\alpha$ (an integer) weight bearing units dominate a segment in $S_{1}$, then $\alpha$ weight bearing units dominate its correspondent in $\mathrm{S}_{2}$.

Transfer ensures that the weight of a vowel (or geminate) remains constant in B and $\mathrm{R}^{11}$ The Cí- reduplicant trivially obeys Transfer because the long vowel in the base has no correspondent in the reduplicant.

(24) No-Long-V, Transfer $>>$ Dependence-DIM

\begin{tabular}{|c|c|c|c|c|}
\hline \multicolumn{2}{|c|}{ s-DIM-duuk ${ }^{\mathrm{w}}$} & No-Long-V & Transfer & Dep-DIM \\
\hline $\mathrm{a}$ & 吼 s-díduuk ${ }^{\mathrm{W}}$ & $*$ & & $*$ \\
\hline b & s-dúduuk ${ }^{\mathrm{w}}$ & $*$ & $* !$ & \\
\hline $\mathrm{c}$ & s-dúuduuk ${ }^{\mathrm{w}}$ & $* ! *$ & & \\
\hline
\end{tabular}

The optimal candidate (a) only contains one long vowel and obeys Transfer at the expense of Dependence-DIM. The suboptimal candidates incur a fatal violation of Transfer (b) and No-Long-V (c).

The preceding analysis shows that the size and fixed segmentism of the diminutive reduplicant are instances of unmarked structure emerging in reduplication.

Diminutive Summary Ranking:

a Shape

Afx $\leq \sigma$, NoCoda $>>$ MAX-DIM

b Fixed Segmentism

No-Skipping, Transfer, *Complex, No-Long-V >> DEP-DIM, MAX-DIM

*Unstress-V >> Align-L(PrWd, Ft), *Stress-schwa >> DEP-DIM, MAX-DIM

The CV shape follows from the size restrictor Af $\leq \sigma$ and NoCoda having precedence over total copy (Max-DIM). The appearance of the fixed segment may be described as 'no copy is better than a bad copy'. Unmarked structure emerges because of higher ranked phono-constraints (*Complex, *Stressed-schwa, No-Long-V), but faithfulness

\footnotetext{
11 Transfer bans shortening and lengthening of vowels. The definition of transfer makes predictions about certain transfer effects. If a language has low-ranked Transfer then we predict that long vowels can shorten as well as short vowels lengthen. So far this prediction is borne out. For B/R correspondence, in Tagalog a long vowel shortens to accomodate a light syllable template and a short vowel lengthens to accomodate a heavy syllable template (Carrier-Duncan 1984). For I/O correspondence, in Luganda closed syllable shortening is associated with some geminate forms, and compensatory lengthening accompanies glide formation (Clements 1986). For O/O correspondence of truncated forms, in Japanese Hypocoristic formation long vowels may shorten and short vowels may lengthen to accommodate the template (Poser 1990; Benua 1995).
} 
also requires good correspondence as indicated by high-ranking No-Skipping and Transfer.

The correct analysis of fixed segmentism is significant to a parallel account of double reduplications because, as I will show, the diminutive faithfulness constraints are lower ranked than distributive ones. Double reduplications exploit this difference in ranking, resulting in the diminutive being less faithful to its base than the distributive in both single and double reduplications.

\subsection{Distributive}

Distributive reduplication indicates plurality and the distribution of items (Bates, Hess and Hilbert 1994). The two productive patterns of the distributive are CVC- and CV-. ${ }^{12}$ First let us examine the CVC- pattern exemplified below.

\section{Lushootseed Distributive}

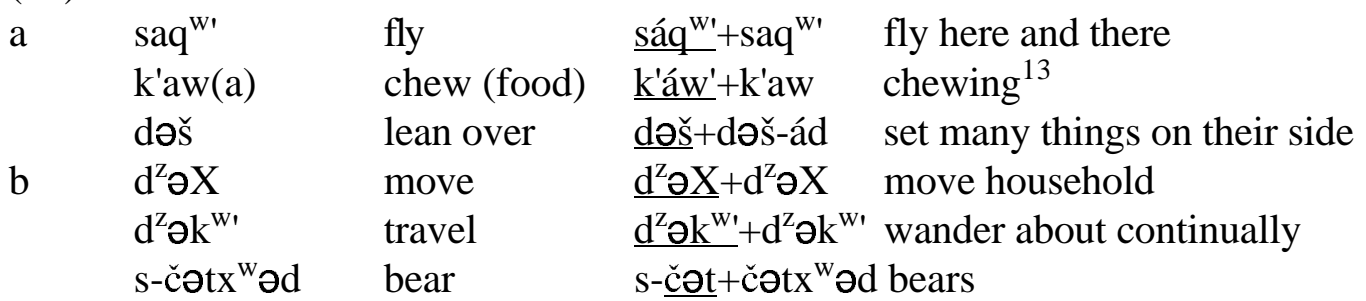

In all cases the distributive is identical to the first CVC of the stem. Like the diminutive, the distributive follows the regular stress pattern of the language. However, unlike the diminutive, schwa can be stressed. This difference will be significant in the analysis of double reduplications. ${ }^{14}$ The preceding pattern illustrates that the distributive is a CVC-prefix.

The CVC- shape results because MAX-DIST dominates NoCoda. The template is analyzed as affixal: RED-DIST $=A f x$. Therefore, Afx $\leq \sigma$ is active in restricting the size of the distributive reduplicant to a syllable.

\footnotetext{
${ }^{12}$ Hess and Hilbert (1976, 2: 161) note that there are two irregular forms of the distributive which occur with high frequency words. A small set have the shape $-\mathrm{VC}_{2^{-}}$, and another small set have a $\mathrm{C}_{1} \theta^{-}$ affix.

13 Hess and Hilbert (1976, 2: 161) note that when the second consonant of the distributive is a sonorant, it is glottalized.

${ }^{14}$ In the stems in (b) *Stressed-schwa is violated and Dep-DIST is obeyed. The ranking between Dependence $_{\text {DIST }}$ and *Stressed-schwa cannot be determined. While suboptimal *bid-bəda? violates DepDIST, it also violates both parts of Contiguity (see MP 1995). Correspondents in the base and reduplicant are discontiguous: only the consonants are in correspondence. Dom(f) is split: $\{b, d\}$, as is Range(f): $\{b, d\}$. A valid ranking argument cannot be obtained because Contiguity (rather than Dependence) could compel violation of *Stressed-schwa.
} 
Afx $\leq \sigma>>$ MAX-DIST $>>$ NoCoda

\begin{tabular}{|c||c|c|c|}
\hline & Afx $\leq \sigma$ & MAX-DIST & NoCoda \\
\hline \hline a 咆 bədbədá? & & $* *$ & $* *$ \\
\hline b bəbədá? & & $* * * !$ & $*$ \\
\hline c bədabədá? & $* !$ & $*$ & $*$ \\
\hline
\end{tabular}

Candidate a. is selected as optimal. Candidate $b$. fares the worst on MAX-DIST. Candidate $\mathrm{c}$. violates $\mathrm{Afx} \leq \boldsymbol{\sigma}$ because it is disyllabic. With high ranking $\mathrm{Afx} \leq \boldsymbol{\sigma}$ and MAX-DIST, the optimal shape of the distributive reduplicant is CVC.

A small number of forms have a CV- alternant: roots in which the first two consonants are identical. This pattern is significant to understanding the CValternant of the double-reduplications. The following is an exhaustive list of stems with (almost) identical initial consonants and their distributive forms.

(28) Distributive: $\mathrm{C}_{1}=\mathrm{C}_{2}$

a)i. c'íc'al long feathers with thick stems

c'íc'íc'al-b sprouted wings

ii. t'it'-əb bathe

t'it'it'-əb bathe for a while

iii. t'uc'-il fire a gun

t'út'c'-il shoot more than once

iv. wíw'su children; little

wíwiw'su little [plural]

v. ləlwá?səd sleeping platform

løləlwá?səd sleeping platforms

b) lil far, far away

?u-lillil-təb they were separated (from rest of group)

In (a) there are five stems which have a CV-reduplicant. However, in (b) there is one stem with a CVC- reduplicant. The regular pattern for stems with identical initial consonants, then, is as in (a): only the first CV- of the root is copied.

A phonological analysis is required to explain why the second consonant does not reduplicate in (28a). A careful examination of the preceding stems, and segmentally similar forms in the Lushootseed Dictionary shows that the identical consonants do not arise from reduplication. Because the forms are not reduplicated, failure to copy the second consonant cannot be due to subjacency as would be expected under Broselow's proposal. Recall that subjacency restricts the copying to the adjacent stem. The non-reduplicated stems are a copying domain. So a phonological analysis is required. 
The failure to copy the second consonant in the distributive is analyzed as an instance of antigemination. If the distributive were the maximal $\mathrm{C}_{1} \mathrm{~V}_{1} \mathrm{C}_{2}$ - prefix, the output would contain two adjacent identical consonants.

$\begin{array}{ll}\text { (29) } & \text { Unattested Distributive Forms } \\ \text { i. } & \text { *c'ic'c'ic'al-b } \\ \text { ii. } & \text { *t'it't'it'-əb } \\ \text { iii. } & \text { *tuc't'uc'-il } \\ \text { iv. } & \text { *wiw'wiw'su } \\ \text { v. } & \text { * } \underline{\text { ləlləlwa?səd }}\end{array}$

Antigemination accounts for all cases of a CV- distributive reduplicant. Thus, high ranked phonological constraints prevent the maximal CVC-distributive affix from occuring whenever the first two consonants of a stem are identical.

Broselow (1983: 326) suggests that a process of antigemination would explain why the distributive is CV- in the DIST-DIM stems. With distributive affixation, the entire diminutive-stem melody is copied. Melodemes are associated to the CVC affix. The form is then subject to a rule of antigemination.
DIST
DIM
Stem
C V C
C V
b i b əda?
b i

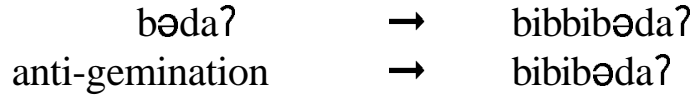

While antigemination accounts for the DIST-DIM pattern of reduplication, Broselow maintains the subjacency analysis. She cites the form in (28b), with the CVC-shape, as evidence against an antigemination rule. As stated above, subjacency cannot derive the $\mathrm{CV}$ - pattern of single reduplications in (28a). I can find no explanation for why both consonants reduplicate in $(28 \mathrm{~b})$, but will adopt the antigemination analysis based on language-internal evidence.

A large amount of evidence supports a general process of antigemination in Lushootseed. Hess (1967: 7) notes that identical stops reduce to a single stop. Snyder (1968: 22) also notes the loss of an identical consonant at morpheme junctures. An examination of the medial clusters in the recently expanded corpus (Bates, Hess, and Hilbert 1994), shows that geminates are extremely rare, limited to: $g^{w} g^{w} q q$ and $l l$. Of the handful of words found with geminates, two have alternate pronunciations which avoid the geminate.

\section{(31) Medial Geminates}

a $\quad$ ?údəg ${ }^{\mathrm{w}}=\mathrm{g}^{\mathrm{w}} \mathrm{iL} \sim$ ?údəg ${ }^{\mathrm{w}}=\mathrm{iL}$ middle of canoe

$$
\lambda \text { 'əlla? } \quad \sim \lambda \text { 'ála after a while }
$$

b $\quad d x^{\mathrm{w}}$-yəq=qíd-əb Speak up!

?u-lílilitəb

they were separated (from rest of group) 
Even when there are identical consonants as in (a), they are avoided by deletion. The virtual lack of geminates provides strong evidence that antigemination accounts for the $\mathrm{CV}$ - distributive.

Two constraints rule out geminate structures: the Obligatory Contour Principle (OCP) and NoLink. The OCP (Leben 1973; Goldsmith 1976; McCarthy 1986) rules out adjacent identical consonants:

Obligatory Contour Principle

At the melodic level, adjacent identical elements are prohibited

NoLink rules out linked structures (Selkirk 1984). ${ }^{15}$

$$
\text { NoLink }
$$

$\alpha$

Gemination satisfies the OCP by linking identical melodemes, but it violates NoLink. Nowhere in the phonology of Lushootseed is there evidence of linking between adjacent consonants. ${ }^{16}$ Antigemination satisfies both the OCP and NoLink: there is only one segment and it is not doubly linked.

High ranking OCP and NoLink compel violation of MAX-DIST. The following tableau shows that MAX-DIST is violated in order to satisfy the OCP and NoLink.

\section{(34) OCP, NoLink >> MAX-DIST}

\begin{tabular}{|c||c|c|c|}
\hline & OCP & NoLink & MAX-DIST \\
\hline \hline a. c'ic'c'ic'al & $* !$ & & $* *$ \\
\hline $\begin{array}{c}\text { b. } \frac{\text { c'ic'c'ic'al }}{V} \\
\text { c. }{ }^{2} \text { c'ic'ic'al }\end{array}$ & & $* !$ & $* *$ \\
\hline
\end{tabular}

${ }^{15}$ While Itô, Mester, and Padgett (forthcoming) propose a family of NoLink constraints, only the most general version is needed for the Lushootseed analysis.

${ }^{16}$ In Lushootseed there is no assimilation between adjacent consonants. There are no nasals, and adjacent segments may differ in glottalization, voicing and place. NoLink is only violated between vowels. There are long vowels as well as a process of vowel harmony in a subset of transitive stems (e.g. bíx ${ }^{\text {wi-d }}$ 'toss it, shake it' BHH94: 41). 
Candidates a. and b. fare the best on MAX-DIST. However, a. violates the OCP and b. violates NoLink. The optimal candidate obeys the OCP and NoLink at the expense of MAX-DIST.

External evidence for antigemination at the reduplicant/base boundary comes from a similar pattern of reduplication in Rotuman, an Austronesian language. Churchward (1940: 103) observes that if reduplication 'results in two identical consonants coming together, the two coalesce into one'. Observe the data below:

(35) Rotuman Reduplication (Churchward 1940: 103)

$\begin{array}{llll}\text { a } & \begin{array}{l}\text { karkarā } \\ \text { barue }\end{array} & \text { karkarkarā } & \text { to snore } \\ \text { čoči } & \text { yarnarue } & \text { to work } \\ \text { kokok̄ō } & \text { ḱoči } & \text { to shave } \\ & \text { kokokā } & \text { to cackle }\end{array}$

In (a) we see the regular pattern is CVC. However in (b), when the first two consonants of the stem are identical, antigemination results in a CV-reduplicant. ${ }^{17}$ Thus cross-linguistic evidence supports the OCP as an active constraint in limiting the size of a reduplicant.

To summarize, the distributive reduplicant is CVC- because MAX-DIST dominates NoCoda. The $\mathrm{CV}$ - alternant results because high ranking constraints barring geminates rule out the CVC- reduplicant in stems with initial identical consonants.

Distributive Summary Ranking

OCP, NoLink, Afx $\leq \sigma>>$ MAX-DIST $>>$ NoCoda

Each of the reduplicative morphemes has been formed in parallel. The input contains the abstract morpheme DIST or DIM, and the output contains a wellformed reduplicant. The overall shape and the presence or absence of fixed segmentism are derived by constraint interaction, according to the assumptions outlined in section 2. In the following section, I will combine the rankings obtained thus far and show that words with two reduplicative morphemes in the input can also be derived in parallel.

\footnotetext{
${ }^{17}$ Interestingly, Rotuman double reduplications are the same as the Lushootseed DIST-DIM stems. (i) Rotuman Double Reduplications (Churchward 1940: 105) 


\section{Double Reduplications}

There are two patterns of double reduplications with diminutive and distributive affixes. ${ }^{18}$ As noted at the outset, the distributive and diminutive affixes may cooccur in either order, producing DIST-DIM and DIM-DIST stems. Some examples of both possible orders are provided below.

Lushootseed Double Reduplications

a

$$
\text { DIM-DIST }
$$

bí-bəd-bəda?

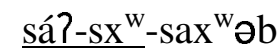

b DIST-DIM

\section{bí-bi-bəda?}

sdí-di-duuk ${ }^{\mathrm{w}}$

č'í-̌́'i-č' $\lambda \mathrm{a}$ ? dolls, litter [of baby animals]

legs partly covered ${ }^{19}$

small children

small knives

gravel

The DIST-DIM stems are the most productive. (This is probably the result of the unusual semantics of forming diminutive-distributives.) In the DIM-DIST stems (a), the size and vowel quality of $\mathrm{R}_{\mathrm{DIM}}$ and $\mathrm{R}_{\text {DIST }}$ are identical to those observed in single reduplications: $C_{1} 1$ and $C_{1} V_{2}$. However, in the DIST-DIM stems in (b), there are three irregularities. The distributive reduplicant does not have the expected shape or segmentism; it is $\mathrm{C}_{1}$ i rather than $\mathrm{C} \mathrm{VC}$. As noted in section 3.2, in single reduplications the distributive maintains schwa, even when stressed. Also, the nucleus of the diminutive reduplicant is $i$ even though it is not stressed. Recall that when the diminutive is unstressed, the nucleus is schwa.

It turns out that the preceding patterns are the result of the distributive reduplicant being more faithful to its base than the diminutive. The ranking of distributive faithfulness over diminutive faithfulness (which is derived from the analysis of the single reduplications) results in the correct shape and fixed segmentism for all reduplication patterns.

In a parallel analysis both reduplicative morphemes are affixed and candidate outputs are evaluated against the constraint hierarchy. The input contains the abstract morphemes DIST and DIM, affixed in an order consistent with the lexical semantics of the word. In the candidate output forms, each reduplicative morpheme has its own reduplicant and base. It is fairly simple to recognize the reduplicants in the output, but is a matter of some delicacy to determine what portion of the output functions as the base for each morpheme. Recall that for prefixing reduplication, the base is the string immediately following the reduplicant. So, in DIST-DIM stems, the base for

\footnotetext{
${ }^{18}$ A third reduplicative morpheme indicating 'out-of-control' is also quite productive, and can occur with distributive or diminutive reduplication.

19 Syncope often accompanies reduplication (Hess 1966). The process is not entirely regular, but occurs most frequently between voiceless obstruents.
} 
the distributive consists of any segments following it; this includes the string comprising the diminutive reduplicant plus stem. The base for the diminutive will be the following stem material. Likewise, in DIM-DIST stems, with the diminutive as the initial reduplicant, its base will contain the following distributive plus stem.

The following representations identify the correspondence relations for DIMDIST and DIST-DIM stems. Correspondents are indexed with numbers for the diminutive morpheme and with lower case letters for the distributive morpheme. Bases are underlined.

a DIM-DIST

R/B Correspondents

input:

output:

$\begin{array}{ll}\text { DIM } & \mathrm{R}_{\text {DIM }} / \underline{\mathrm{B}}_{\text {DIM }} \\ \text { DIST } & \mathrm{R}_{\mathrm{DIST}} / \underline{\mathrm{B}}_{\mathrm{DIST}}\end{array}$

$\mathrm{RED}_{\mathrm{DIM}^{-}} \quad \mathrm{RED}_{\mathrm{DIST}^{-}} \quad$ bəda?

bi bəd bəda?

DIST $\mathrm{R}_{\mathrm{DIST}} / \underline{\mathrm{B}}_{\mathrm{DIST}}$

$1 \underline{123} \underline{45678}$

abc abcde

b DIST-DIM

input:

output:

DIST $\mathrm{R}_{\text {DIST }} \underline{B}_{\text {DIST }}$

DIM $\quad \mathrm{R}_{\mathrm{DIM}} \underline{\mathrm{B}}_{\mathrm{DIM}}$

$\begin{array}{lll}\text { RED }_{\text {DIST }^{-}} & \text {RED }_{\text {DIM }^{-}} & \text {bəda? } \\ \text { bi } & \text { bi } & \text { bəda? } \\ \mathrm{ab} & \underline{\mathrm{ab}} & \underline{\text { cdefg }} \\ & 1 & \underline{12345}\end{array}$

Comparing the distributive correspondence relations in (a) and (b) shows that the distributive reduplicant only contains base segments. On the other hand, in the diminutive correspondence relations in (a) and (b), the reduplicants contain non-base segments.

To preview the analysis, regardless of affix order, the diminutive reduplicant violates DEP-DIM, and the distributive reduplicant obeys DEP-DIST. This is an important result. The fact that one reduplicative morpheme obeys a faithfulness constraint while another one violates it, provides evidence for separate correspondence functions for individual reduplicative morphemes. Further, the identity between reduplicants in DIST-DIM stems is the result of maintaining identity between distributive base and reduplicant.

As predicted by parallelism, the representations in (38) are the optimal candidates when evaluated against the entire constraint hierarchy. The shape and fixed segmentism in the output are consistent with the constraint rankings established for single reduplications. In all cases the output obeys distributive faithfulness at the expense of diminutive faithfulness. Let us first examine shape and then fixed segmentism. 


\subsection{Shape}

Constraints interact with MAX to determine the size of the reduplicants. By transitivity of constraint ranking (MAX-DIST $>$ NoCoda and NoCoda $\gg$ MAXDIM) we arrive at the following hierarchy.

\section{OCP/NoLink ${ }^{20}>>$ MAX-DIST $>>$ NoCoda $>>$ MAX-DIM}

The syllable structure constraint which distinguishes the shape of the distributive and diminutive reduplicants (presence vs. absence of a coda) intervenes between MAXDIST and MAX-DIM.

In the single reduplications, the basic shapes of the diminutive and distributive are $\mathrm{C}_{1} \mathrm{~V}$ - and $\mathrm{C}_{1} \mathrm{VC}_{2^{-}}$. For the double reduplications there are four candidate shapes to be compared: $\mathrm{C}_{1} \mathrm{~V}-\mathrm{C}_{1} \mathrm{VC}_{2^{-}}, \mathrm{C}_{1} \mathrm{VC}_{2}-\mathrm{C}_{1} \mathrm{VC}_{2^{-}}, \mathrm{C}_{1} \mathrm{VC}_{1}-\mathrm{C}_{1} \mathrm{~V}-{ }^{21}$ and $\mathrm{C}_{1} \mathrm{~V}-\mathrm{C}_{1} \mathrm{~V}-$. In both DIST-DIM and DIM-DIST stems, the optimal candidate obeys the OCP/NoLink; it violates MAX-DIST and NoCoda only minimally, and fares poorly on MAX-DIM.

The optimal shape of the reduplicants in DIST-DIM stems is $\mathrm{C}_{1} \mathrm{~V}-\mathrm{C}_{1} \mathrm{~V}$-. In the following tableau the vowel quality is held constant, but the shape varies among the candidates.

(40) DIST-DIM
\begin{tabular}{|c||c|c|c|c|}
\hline DIST-DIM-bəda? & OCP/Nolink & MAX-DIST & NoCoda & MAX-DIM \\
\hline \hline a. bí-bid-bəda? & & $* * * * * * !$ & $* *$ & $* * *$ \\
\hline b. bíd-bid-bəda? & & $* * * * *$ & $* * * !$ & $* * *$ \\
\hline c. bíb-bi-bəda? & $* !$ & $* * * *$ & $* *$ & $* * * *$ \\
\hline d. $\quad$ bí-bi-bəda? & & $* * * * *$ & $*$ & $* * * *$ \\
\hline
\end{tabular}

Candidate $d$. best satisfies the constraint hierarchy. Candidate a. violates MAX-DIST worse than others. The distributive reduplicant is bi, its base bidb ada? Candidate b. violates NoCoda more than minimally, and candidate c. fatally violates the

\footnotetext{
${ }^{20}$ I will refer to the constraints OCP and NoLink as OCP/NoLink in order to econominally examine the candidates with geminates and adjacent identical consonants. In the tableaus only one candidate, not two, will show violations of OCP/NoLink.

${ }^{21}$ In the $\mathrm{C}_{1} \mathrm{VC}_{1}-\mathrm{C}_{1} \mathrm{~V}$ - pattern, the outer reduplicant contains two identical consonants because its base contains two identical consonants: base $=\mathrm{C}_{1} \mathrm{VC}_{1} \mathrm{~V}\left(\mathrm{C}_{2} \ldots\right)$. The base contains the inner reduplicant and the following stem. In strict prefixing reduplication, when a larger reduplicant precedes a smaller reduplicant, the larger reduplicant will always contain two identical consonants.
} 
OCP/NoLink. In the optimal candidate, minimizing MAX-DIST violations leads to greater MAX-DIM violation (but MAX-DIM is irrelevant).

The comparison of candidates a. and d. shows a remarkable effect of parallelism. Candidate a. is suboptimal because of MAX-DIST, and yet a. and d. differ in the size of the diminutive reduplicant. The correct size of the diminutive reduplicant is achieved by a higher ranked constraint which does not directly evaluate diminutive correspondence. An interaction exists because the distributive base contains the diminutive reduplicant. In a serial derivation, the interaction between MAX-DIST and the size of the diminutive reduplicant is unexplainable. In a parallel derivation one expects high ranking constraints to exert an effect over the entire word.

As a point of logic, a serial derivation would not need to explain such an interaction. The optimal diminutive form would be derived, and would serve as the input for distributive reduplication. A potential problem facing the serial account is that the input to distributive formation, bíbadà?, contains structure that would need to be erased. First, primary stress, but not secondary stress, would need to be reassigned. Second, in order for there not to be an interaction of the type seen in the preceding tableau, the correspondence relation between the diminutive reduplicant and base would also need to be erased. Otherwise Gen could change the exponence of the diminutive morpheme, and an interaction between MAX-DIST and the diminutive reduplicant would occur. These two changes to the diminutive stem are unnecessary complications to the grammar, given that parallelism derives the correct forms. While the serial account would not need to explain the interaction between MAX-DIST and the diminutive reduplicant, it would need to explain why the relation between reduplicant and base is obliterated between levels. A further problem is that there is no evidence for intermediate stages, because the constraint rankings do not differ. Serialism would also posit an intermediate stage for DIM-DIST stems, where the input to diminutive is the distributive stem $b$ adbədá?.

The optimal shape of the reduplicants in DIM-DIST stems is $\mathrm{C}_{1} \mathrm{~V}-\mathrm{C}_{1} \mathrm{VC}_{2^{-}}$, which also follows from the constraint ranking established for single reduplications. (41) DIM-DIST

\begin{tabular}{|c||c|c|c|c|}
\hline DIM-DIST-bəda? & OCP/NoLink & MAX-DIST & NoCoda & MAX-DIM \\
\hline \hline a. 味占í-bəd-bəda? & & $* *$ & $* *$ & $* * * * * * *$ \\
\hline b. bíd-bəd-bəda? & & $* *$ & $* * * !$ & $* * * * * *$ \\
\hline c. bíb-bə-bəda? & $* !$ & $* * *$ & $* *$ & $* * * * *$ \\
\hline d. bí-bə-bəda? & & $* * * !$ & $*$ & $* * * * * *$ \\
\hline
\end{tabular}

Candidate a. best satisfies the constraint hierarchy. The suboptimal candidates incur fatal violations of NoCoda (b), OCP/NoLink (c), and MAX-DIST (d). 
Regardless of affix order, the four candidate shapes can be winnowed down to two, based on purely phonological grounds. Candidates with $\mathrm{C}_{1} \mathrm{VC}_{2}-\mathrm{C}_{1} \mathrm{VC}_{2}$ shape incur a fatal violation of NoCoda. Candidates with $\mathrm{C}_{1} \mathrm{VC}_{1}-\mathrm{C}_{1} \mathrm{~V}$ shape incur a fatal violation of OCP/NoLink. Of the two remaining candidate shapes, $\mathrm{C}_{1} \mathrm{~V}-\mathrm{C}_{1} \mathrm{~V}$ and $\mathrm{C}_{1} \mathrm{~V}-\mathrm{C}_{1} \mathrm{VC}_{2}$, both share the property that the initial reduplicant has the shape $\mathrm{C}_{1} \mathrm{~V}$. Selection of the optimal candidate thus rests on selecting the correct shape for the second reduplicant.

The optimal reduplicant shapes obey MAX-DIST at the expense of MAXDIM. An interaction occurs because the the base of the outer reduplicant contains the segments of the inner reduplicant: there is a direct relationship between the size of reduplicants and bases. When DIST is outermost, its base contains diminutive material. Here, obeying MAX-DIST coincides with minimizing the size of the distributive base, reducing the size of the diminutive reduplicant. A smaller diminutive reduplicant incurs more MAX-DIM violations. So the optimal DIST-DIM stem is $\mathrm{C}_{1} \mathrm{~V}-\mathrm{C}_{1} \mathrm{~V}$-, with a smaller diminutive reduplicant. When DIM is outermost, its base contains distributive material. Obeying MAX-DIST results in increasing the size of the distributive reduplicant; its base remains constant. A larger distributive reduplicant coincides with a larger diminutive base and a greater number of MAXDIM violations, making the optimal DIM-DIST candidate $\mathrm{C}_{1} \mathrm{~V}-\mathrm{C}_{1} \mathrm{VC}_{2^{-}}$.

The correct shapes of the reduplicative morphemes can be derived in parallel, regardless of the order of reduplicative affixes. Nothing special need be said about words with multiple reduplicative affixes. The only requirement is that the input have the correct morphological structure. Everything else follows from the constraint ranking independently required for single reduplications. Having established that shape can be derived in parallel I now turn to fixed segmentism.

\subsection{Fixed segmentism}

Recall that fixed segmentism results in a violation of Dependence. In order to derive the correct pattern of fixed segmentism we must establish an overall ranking of the different Dependence constraints for diminutive and distributive morphemes. I will limit the discussion to the stems which contain schwa vowels.

In the analysis of the diminutive, I established that the phono-constraint *Stressed-schwa dominates DEP-DIM. Recall that the difference between diminutive and distributive was that the distributive reduplicant tolerated stressed schwas. However, no ranking between DEP-DIST and *Stressed-schwa was provided because, as mentioned in note 14 in section 3.2, the crucial candidate *bid-b $2 d a ?$ also violates Contiguity-DIST. Therefore, the ranking of Dependence-DIST and *Stressed-schwa cannot be determined. However, when the distributive reduplicant is CV- (as in the DIST-DIM stems), Contiguity is trivially obeyed, establishing the following ranking: 


\section{Dependence-DIST, *Stressed-ə >> Dependence-DIM}

It is important to keep in mind that the addition of the distributive morpheme will not affect initial stress. ${ }^{22}$ So, in the following discussion, stress remains on the initial syllable in accordance with Align(PrWd, L, Ft, L).

Because we are only examining roots with schwa, there are two vowel qualities to consider: the root vowel $\partial$ or the fixed segment $i$. Freely generating all relevant candidates produces four possible vowel melodies for the double reduplications: $\boldsymbol{\theta}-\boldsymbol{\partial}, \boldsymbol{i}-\boldsymbol{\partial}, \boldsymbol{\partial} \boldsymbol{i}$, and $i-i$. The optimal candidate will obey DependenceDIST and *Stressed-schwa, faring poorly on Dependence-DIM. The prediction is that for all stems, the distributive reduplicant will only contain base material and the diminutive will always contain non-base material.

The optimal shape for DIST-DIM stems is $\mathrm{C}_{1} \mathrm{~V}-\mathrm{C}_{1} \mathrm{~V}$ as I have already established. In the following tableau the shape is held constant, but the vowel quality varies among the candidates.

\section{(43) DIST-DIM}

\begin{tabular}{|lc||c|c|c|}
\hline \multicolumn{1}{|c||}{ DIST-DIM-Root } & Dep-DIST & $*$ Stressed-ə & Dep-DIM \\
\hline \hline a. $\quad$ bə-bə-bəda? & & $* !$ & \\
\hline b. $\quad$ bí-bə-bəda? & $* !$ & & \\
\hline c. $\quad$ bə-bi-bəda? & $* !$ & $* !$ & $*$ \\
\hline d. 0 bí-bi-bəda? & & & $*$ \\
\hline
\end{tabular}

Candidate $\mathrm{d}$. is the optimal form. It only violates Dep-DIM. The distributive reduplicant is $b i$; its base bibəda?. Dep-DIM is violated because the diminutive reduplicant is $b i$, containing a segment not in its base $b \partial d a$ ? The suboptimal candidates violate *Stressed-schwa (a), Dependence-DIST (b), or all three constraints (c). Once again, distributive faithfulness is maintained over diminutive faithfulness.

The preceding tableau illustrates that Dependence-DIST dominates Dependence-DIM. A valid ranking argument obtains because all candidates obey Contiguity-DIST. The ranking is determined by comparing candidates $b$. and $d$. repeated in the tableau below.

\footnotetext{
${ }^{22}$ Forms like /bədbədá?/ are analyzed as having an initial foot that does not bear main stress. The initial foot satisfies Align-L(PrWd, Ft) and the lack of stress satisfies *Stressed-schwa. For further details about Lushootseed prosody, see Urbanczyk (in prep).
} 
(44) Dependence-DIST >> Dependence-DIM

\begin{tabular}{|c|c|c|c|}
\hline \multicolumn{2}{|c|}{ DIST-DIM-Root } & Dependence-DIST & Dependence-DIM \\
\hline b. & bí-bə-bəda? & $* !$ & \\
\hline d. & bí-bi-bəda? & & $*$ \\
\hline
\end{tabular}

In the optimal candidate, every segment of the distributive has a correspondent in its base. Higher ranking Dependence-DIST compels violation of Dependence-DIM, resulting in identity between the distributive and its base, which contains the diminutive reduplicant. This identity effect explains why the diminutive has the fixed segment even though it is not stressed.

The identity between the distributive and diminutive reduplicant is an instance of over-application of fixed segmentism (as pointed out to me by Laura Walsh). Over-application occurs when a phonological alternation applies in both base and copy, even though the trigger is present in only one string (Wilbur 1973; Kiparsky 1986; Mester 1986; McCarthy and Prince 1995). A classic case of over-application can be seen in the Indonesian nasal substitution below.

(45) Indonesian Nasal Substitution (Uhrbach 1987; McCarthy and Prince 1995)

pikir məmikir məmikir-mikir think (over)

tari mənari mənari-nari dance (for joy)

kira məyira məyira-yira approximately/to guess

Over-application results because identity is maintained between reduplicant and base. See McCarthy and Prince (1995) for detailed discussion of reduplicative overapplication and Benua (1995) for over-application in truncated words.

The ranking for over-application of fixed segmentism in double reduplications shows remarkable parallels with the ranking established for over-application in single reduplications (McCarthy and Prince 1995) and in truncated words (Benua 1995). The ranking schemata are presented below.

(46) Over-application Schemata

a Single Reduplications (McCarthy and Prince 1995)

BR-Faith, Phono-Constraint >> IO-Faith

b Truncated Words (Benua 1995)

BT-Faith, Phono-Constraint >> IO-Faith

c Double Reduplications

Dependence-DIST, *Stressed-ə >> Dependence-DIM

In all cases of over-application, high-ranked reduplicative (and truncatory) faithfulness compels violation of lower-ranked base faithfulness. In single reduplications and truncated words, the faithfulness of the base is regulated by IO-Correspondence, 
while in double reduplications, the faithfulness of the base is regulated by BRCorrespondence.

In the DIST-DIM stems, initial stress compels the presence of a fixed segment. Because DEP-DIST is high ranking, it compels the presence of the fixed segment in its base. which contains the diminutive reduplicant.

The pattern of fixed segmentism in DIM-DIST stems also follows from the same ranking. Recall that the optimal shape is $\mathrm{C}_{1} \mathrm{~V}-\mathrm{C}_{1} \mathrm{VC}_{2}$; again, only vowel quality varies among the candidates.

\begin{tabular}{|c|c|c|c|}
\hline DIM-DIST-Root & Dep-DIST & *Stressed-ə & Dep-DIM \\
\hline a. bə-bəd-bəda? & & $* !$ & \\
\hline b. 味兰í-bəd-bəda? & & & $*$ \\
\hline c. bə-bid-bəda? & $* !$ & *! & $*$ \\
\hline d. bí-bid-bəda? & $* !$ & & \\
\hline
\end{tabular}

Candidate a. violates *Stressed-schwa and candidates c. and d. violate DependenceDIST. Candidate $\mathrm{b}$. is optimal because $\mathrm{R}_{\mathrm{DIST}}$ only contains base material $\left(\mathrm{R}_{\mathrm{DIST}}=b \partial d\right.$; $\mathrm{B}_{\mathrm{DIST}}=b \partial d a$ ?).

Over-application does not apply in DIM-DIST stems because the diminutive base (the distributive reduplicant) has a stronger faithfulness requirement. The distributive must be faithful to its base, which is regulated by IO-Faith.

Regardless of affix order, the correct pattern of fixed segmentism is selected because the distributive maintains identity with its base, while the diminutive is always unfaithful to its base. High-ranking Align(PrWd, L, Ft, L) and *Stressed-schwa ensure that the initial reduplicant is always Cí. Thus the two vowel melodies to choose from are: $i-i$ and $i$ - $\partial$. When distributive is outermost (DIST-DIM), the identical vowel melody is optimal. Fixed segmentism over-applies. When the diminutive is outermost (DIM-DIST), the non-identical vowel melody is optimal. There is normal application of fixed segmentism. In both DIST-DIM and DIM-DIST stems, obeying Dependence-DIST results in violation of Dependence-DIM.

\subsection{Summary}

I have shown that parallelism of constraint evaluation results in the correct shape and fixed segmentism in double reduplications. Previous accounts required 
cyclicity and subjacency. Subjacency is inappropriate to account for the CV-alternant in the DIST-DIM stems because a process of antigemination explains the pattern. Further, subjacency cannot account for the CV- alternants which occur with single reduplications. Cyclicity is not needed because with the advent of Correspondence Theory, reduplicant and base are necessarily adjacent in the output. ${ }^{23}$ Recall that in Broselow's analysis cyclic reduplication ensured that the segmental content of the affix was obtained from an adjacent string. In addition, the identity effect, previously attributed to the cycle, is reanalyzed as an instance of over-application.

The DIST-DIM pattern of double reduplication seemed to provide evidence for an intermediate stage in the derivation. A serial analysis would posit an intermediate stage in which DIM is affixed first. However, we saw that the distributive constraint exerts an influence over the diminutive shape and fixed segmentism.

One final point is that the constraint rankings for the two reduplicative affixes follow a pattern: the distributive R/B correspondence constraints dominate the diminutive ones. This is schematized as:

\section{DIST-Faith >> DIM-Faith}

The distributive reduplicant is more faithful to its base than the diminutive: it contains more segments and contains only base material.

Two questions arise regarding the ranking in (48). The first is why the ranking should be as it is, and the second concerns encoding this relative ranking in the lexical entries of reduplicative affixes. The answer to both of these questions is the same if the distributive morpheme is a root reduplicant. Specifying the distributive template as $\mathrm{RED}_{\mathrm{DIST}}=$ Root rather than $\mathrm{RED}_{\mathrm{DIST}}=\mathrm{Afx}$ proves to be an instance of the general schema:

${ }^{23}$ Adjacency of reduplicant and base is problematic for double reduplications with a reduplicative infix. The reduplicative infix is not part of the base, as the following DIST-DIM stems from Thompson (Interior Salish) show.

(i) Thompson (Broselow 1983: 329)

a sil calico

b $\underline{\text { sí-sil DIM }}$

c sil-sil DIST

d sil-sí-sil DIST-DIM

It appears as if the segments of the diminutive affix (an infix) are skipped over in (id). This pattern also violates subjacency because the distributive contains segments from a non-adjacent stem. Broselow attributes the transparency of the diminutive to its status as an infix. She proposes that the diminutive attaches to a syllable (the locus of its attachment site is sensitive to stress) and does not produce a new stem, making it exempt from the subjacency condition. Following Broselow's insight, Urbanczyk (in prep) investigates the morphological vs. prosodic conditions on bases, to explain why infixes are not part of the base. This pattern does not offer evidence for a serial derivation because it is not clear which stem has precedence (DIM or DIST) in forming double reduplications. 
The fact that distributive correspondence dominates diminutive correspondence follows from the universal ranking in (49). McCarthy and Prince (1995) propose that correspondence holds between input and output, as well as between base and reduplicant. If the distributive is a root and the diminutive is an affix, then the ranking in (48) is an instantiation of (49). The two faithfulness schemata refer to the same set of constraints, the only difference is that one measures $\mathrm{I} / \mathrm{O}$ faithfulness and the other measures B/R faithfulness. (See MP 1995 for a discussion of other possible interactions between correspondence constraints.)

Analyzing the distributive template as a Root proves to be an enterprise in its own right. Therefore I will just mention some of the issues which are raised by this proposal.

The first issue is to determine the constraints that characterize root shape. The analysis thus far assumes that the distributive is an affix, and therefore its syllable size obeys Afx $\leq \sigma$. While McCarthy and Prince (1994a) discuss several constraints on the shape of Stem and Affix, it is more problematic to provide a uniform theory for roots. For example, it does not seem possible to reconcile concatenative morphological systems such as English with non-concatenative morphological system like Arabic. A key issue is to determine the constraints on canonical root shape and how they affect the size of reduplicative affixes.

The second issue is to provide evidence that the distributive morpheme exhibits rootlike properties in Lushootseed. First, the canonical root shape in Lushootseed is CVC. Snyder (1968: 14) reports that $68 \%$ of the 700 roots he collected are $\mathrm{CVC}$ and $\mathrm{C} \partial \mathrm{C}$ (Southern Lushootseed). So, the distributive has the canonical root shape. Second, Broselow (1983: 337) proposes that the morphological structure of inherently reduplicated words like pišpiš 'cat' is root+root.

$\begin{array}{lll}\text { root } & \text { stem } & \\ \text { piš } & & \text { root } \\ & & \text { piš }\end{array}$

While a systematic study of inherently reduplicated words in Lushootseed has not yet been conducted, Broselow's proposal supports analyzing the distributive morpheme as a segmentally empty root. Third, the distributive exhibits the prosodic properties of roots. Two points are that, in post-tonic position, both roots and distributives may have syncopated vowels, and both allow schwa to be stressed.

Further investigation is required to provide conclusive evidence that the distributive is a root. The proposal has the advantage that the faithfulness requirements of the distributive and diminutive follow a universal ranking schema. 
The individual properties of size and fixed segmentism follow from the universal ranking of root faithfulness over affix faithfulness.

\section{Concluding remarks}

The analysis of double reduplications in parallel has shown some striking results. Primarily, a pattern of reduplication which seemed to present evidence for an intermediate stage (DIST-DIM) actually shows that high ranking reduplicative constraints exert an effect on unrelated reduplicative morphemes. This is quintessential parallelism. If the double reduplications were truly derived with an intermediate stage, a subsequent reduplicative morpheme could not disrupt the results of the first stage.

The patterns of Lushootseed double reduplication illustrate that in serial theories of reduplication (with an actual copy mechanism), the cycle is required to ensure that reduplicant and base are adjacent. In parallel OT, the adjacency of reduplicant and base in the output obviates the need for cyclicity.

Identity effects which had previously been attributed to the cycle are shown to be an instance of over-application of fixed segmentism in double reduplications. When the morpheme with higher-ranked faithfulness requirements precedes the morpheme with lower-ranked faithfulness, identity is enforced. This pattern of overapplication shows striking parallels with identity effects in single reduplications and truncated words. It further shows that the crucial ranking is with RED-Faith dominating BASE-Faith. BASE-Faith can be regulated by IO-Correspondence or BR-Correspondence.

Finally, regardless of the morphological structure of the input, the Constraint Hierarchy (or grammar) of Lushootseed selects the correct candidates for all patterns of reduplication. Any alternations in size and fixed segmentism of the reduplicants follow from the interaction of general phonotactic constraints with reduplication specific constraints. This parallel analysis has been argued to be simpler than a serial account which would posit an unwarranted intermediate stage.

\section{References}

Bates, Dawn. 1986. An analysis of Lushootseed diminutive reduplication. Proceedings of the Twelfth Annual Meeting of the Berkeley Linguistics Society: 1-12.

Bates, Dawn, Thom Hess, and Vi Hilbert. 1994. Lushootseed Dictionary. Seattle: University of Washington Press.

Benua, Laura. 1995. 'Identity effects in morphological truncation'. In Jill Beckman, Laura Walsh Dickey, and Suzanne Urbanczyk eds.,. University of Massachusetts 
Occasional Papers 18: Papers in Optimality Theory. Amherst, MA: Graduate Linguistics Students Association.

Blevins, Juliette. 1994. The bimoraic foot in Rotuman phonology and morphology. Oceanic Linguistics 33.

Broselow, Ellen I. 1983. Salish double reduplications: subjacency in morphology. Natural Language and Linguistic Theory 1: 317-346.

Broselow, Ellen I. and John J. McCarthy. 1984. A theory of internal reduplication. The Linguistic Review 3: 25-88.

Carrier-Duncan, Jill. 1984. Some problems with prosodic accounts of reduplication. In Mark Aronoff and Richard T. Oehrle eds., Language Sound Structure: Studies in Phonology Presented to Morris Halle by His Teacher and Students. Cambridge MA: The MIT Press. Pp. 260-286.

Churchward, C. Maxwell. 1940 [1978] Rotuman Grammar and Dictionary. Sidney: Australasian Medical Publishing Co. [Repr. AMS Press, New York]

Clements, G. N. 1985. The problem of transfer in nonlinear morphology. Cornell Working Papers in Linguistics, 7, 38-73.

Clements, G. N. 1986. Compensatory lengthening and consonant gemination in Luganda. In Leo Wetzels and Engin Sezer eds., Studies in Compensatory Lengthening. Dordrecht: Foris Publications. Pp. 37-77.

Clements, G. N. to appear. Place of articulation in consonants and vowels: a unified theory. In B. Laks and A. Railland eds., L'Architecture et la Géometrie des Représentations Phonologiques. Paris: Editions du C.N.R.S.

Cohn, Abigail. 1989. 'Stress in Indonesian and bracketing paradoxes'. Natural Language and Linguistic Theory 7: 167-216.

Davis, Stuart. 1988. On the nature of internal reduplication. Theoretical Morphology: 305-323.

Goldsmith, John. 1976. Autosegmental Phonology. [Unpublished Ph.D. dissertation, MIT.]

Haeberlin, Herman K. 1918. Types of reduplication in the Salish dialects. International Journal of American Linguistics 1: 154-174.

Hayes, Bruce. 1980. A Metrical Theory of Stress Rules. [Unpublished Ph.D dissertation, MIT.]

Hess, Thom. 1966. Snohomish chameleon morphology. International Journal of American Linguistics 32. 350-356.

Hess, Thom. 1967. Snohomish Grammatical Structure. Unpublished Ph.D dissertation. University of Washington.

Hess, Thom. 1976. Dictionary of Puget Salish. Seattle: University of Washington Press.

Hess, Thom. 1977. Lushootseed dialects. Anthropological Linguistics 19: 403-419. Hess, Thom and Vi Hilbert. 1976. Lushootseed 1 and 2. Seattle: Daybreak Press, United Indians of All Tribes Federation.

Itô, Junko, and R. Armin Mester. 1993. Licensed segments and Safe Paths. Canadian Journal of Linguistics 38: 197-213.

Itô, Junko, and R. Armin Mester. 1995. Realignment. to appear in René Kager, Harry van der Hulst, and Wim Zonneveld eds., Procedings of the Utrecht Prosodic Morphology Workshop [exact title unknown]. 
Itô, Junko, R. Armin Mester, and Jaye Padgett. to appear. NC: Licensing and Underspecification in Optimality Theory. Linguistic Inquiry 26.

Kager, René. 1991. Dutch schwa in moraic phonology. Papers from the 26th Regional Meeting of the Chicago Linguistic Society, Part II. Chicago: CLS, 241255.

Kenstowicz, Michael. 1994a. Cyclic vs. noncyclic constraint evaluation. MIT Working Papers in Linguistics 21: 11-42.

Kenstowicz, Michael. 1994b. Sonority-driven stress. [Unpublished MS., MIT.]

Kiparsky, Paul. 1982. 'Lexical Morphology and Phonology. In Linguistic Society of Korea ed., Linguistics in the Morning Calm. Pp. 3-91.

Kiparsky, Paul. 1986. The phonology of reduplication. ms. Stanford University.

Kirkham, Sandra. 1992. Reduplication in Lushootseed: A Prosodic Analysis. [Unpublished M.A. thesis, University of Victoria.]

Leben, William. 1973. Suprasegmental phonology. [Unpublished Ph.D. dissertation, MIT.]

Levin, Juliette. 1983. Reduplication and prosodic structure. [Unpublished MS., MIT.] Marantz, Alec. 1982. Re Reduplication. Linguistic Inquiry 13: 435-482.

McCarthy, John J. 1986. OCP effects: gemination and antigemination. Linguistic Inquiry 17: 207-263.

McCarthy, John J. and Alan S. Prince. 1986. Prosodic Morphology. ms. University of Massachusetts, Amherst, and Brandeis University.

McCarthy, John J. and Alan S. Prince. 1988. Quantitative transfer in reduplicative and templatic morphology. In Linguistics Society of Korea ed, Linguistics in the Morning Calm 2. Seoul: Hanshin Publishing Company. Pp. 3-35.

McCarthy, John J. and Alan S. Prince. 1990. Foot and word in prosodic morphology: the Arabic broken plural. Natural Language and Linguistic Theory 8: 209-282.

McCarthy, John J. and Alan S. Prince. 1993. Prosodic Morphology I: Constraint interaction and satisfaction. [Unpublished MS., University of Massachusetts at Amherst and Rutgers University.]

McCarthy, John J. and Alan S. Prince. 1994a. An overview of Prosodic Morphology: Parts I and II. [Talks presented at the OTS/HIL Workshop on Prosodic Morphology, Utrecht.]

McCarthy, John J. and Alan S. Prince. 1994b. Emergence of the unmarked: optimality in Prosodic Morphology. In Mercè Gonzàles ed., Proceedings of the Northeast Linguistic Society 24. Amherst, MA: Graduate Linguistic Student Association. 333-379.

McCarthy, John J. and Alan S. Prince. 1995. Faithfulness and reduplicative identity. In Jill Beckman, Laura Walsh Dickey, and Suzanne Urbanczyk, eds., University of Massachusetts Occastional Papers in Linguistics 18: Papers in Optimality Theory. Amherst, MA: Graduate Linguistic Student Association.

Mester, Ralf-Armin. 1986. Studies in Tier Structure. [Unpublished Ph.D. dissertation, University of Massachusetts Amherst.]

Mohanan, K. P. 1986. The Theory of Lexical Phonology. Dordrecht: D. Reidel Publishing Co.

Poser, William J. 1990. Evidence for foot structure in Japanese. Language 66, 78105. 
Prince, Alan S. and Paul Smolensky. 1993. Optimality Theory: Constraint Interaction in Generative Grammar. [Technical Report \#2 of the Rutgers Center for Cognitive Science, Rutgers University.]

Rosenthall, Samuel. 1994. Vowel/glide alternation in a Theory of Constraint Interaction.. [Unpublished Ph.D. dissertation, University of Massachusetts.]

Selkirk, Elisabeth, O. 1977. The French foot: on the status of 'MUTE' e. Studies in French Linguistics 1: 141-150.

Selkirk, Elisabeth O. 1984. On the major class features and syllable theory. In Mark Aronoff and Richard T. Oehrle eds., Language Sound Structure: Studies in Phonology Presented to Morris Halle by His Teacher and Students. Cambridge, MA: MIT Press. Pp. 107-136.

Shaw, Patricia A. 1995. Minimality and markedness. In René Kager, Harry van der Hulst, and Wim Zonneweld eds., Proceedings of the Utrecht Prosodic Morphology Workshop. [exact title unknown].

Snyder, Warren. 1968. Southern Puget Sound Salish: Phonology and Morphology. Sacramento: Sacramento Anthropological Society, Paper 8.

Steriade, Donca. 1988. Reduplication and syllable transfer in Sanskrit and elsewhere. Phonology 5: 73-155.

Uhrbach, Amy. 1987. A formal Analysis of Reduplication and its Interaction with Phonological and Morphological Processes. Unpublished Ph.D. dissertation. University of Texas, Austin.

Urbanczyk, Suzanne. 1994. Template violation in reduplication. Talk presented at the OTS/HIL Workshop on Prosodic Morphology, University of Utrecht.

Urbanczyk, Suzanne. in prep. Patterns of reduplication in Coast Salish. [Unpublished Ph.D. dissertation, University of Massachusetts, Amherst.]

Whitney, Dwight. 1889 [1973]. Sanskrit Grammar. [Thirteenth issue of the second edition.] Cambridge: Harvard University Press.

Wilbur, Ronnie. 1973. The Phonology of Reduplication. [Unpublished Ph.D. dissertation, University of Illinois, Urbana-Champaign.]

Department of Linguistics

The University of British Columbia

Buchanan Building C369

1866 Main Mall

Vancouver, British Columbia

Canada V6T 1 Z1 